\title{
Predictors of Postpartum Glucose Tolerance Testing in Italian Women with Gestational Diabetes Mellitus
}

\author{
Carmelo Capula, ${ }^{1}$ Eusebio Chiefari, ${ }^{2}$ Anna Vero, ${ }^{1}$ Stefania Iiritano, ${ }^{2}$ Biagio Arcidiacono, ${ }^{2}$ \\ Luigi Puccio, ${ }^{1}$ Vittorio Pullano, ${ }^{1}$ Daniela Foti, ${ }^{2}$ Antonio Brunetti, ${ }^{2}$ and Raffaella Vero ${ }^{1}$ \\ ${ }^{1}$ Complex Operative Structure Endocrinology-Diabetology, Hospital Pugliese-Ciaccio, 88100 Catanzaro, Italy \\ ${ }^{2}$ Department of Health Sciences, University "Magna Grocia” of Catanzaro, 88100 Catanzaro, Italy
}

Correspondence should be addressed to Antonio Brunetti; brunetti@unicz.it

Received 3 June 2013; Accepted 30 June 2013

Academic Editors: C. Bizzarri and J. Pachucki

Copyright (c) 2013 Carmelo Capula et al. This is an open access article distributed under the Creative Commons Attribution License, which permits unrestricted use, distribution, and reproduction in any medium, provided the original work is properly cited.

\begin{abstract}
Postpartum screening is critical for early identification of type 2 diabetes in women previously diagnosed with gestational diabetes mellitus (GDM). Nevertheless, its rate remains disappointingly low. Thus, we plan to examine the rate of postpartum glucose tolerance test (ppOGTT) for Italian women with GDM, before and after counseling, and identify demographic, clinical, and/or biochemical predictors of adherence. With these aims, we retrospectively enrolled 1159 women with GDM, in Calabria, Southern Italy, between 2004 and 2011. During the last year, verbal and written counseling on the importance of followup was introduced. Data were analyzed by multiple regression analysis. A significant increase of the return rate was observed following introduction of the counseling [adjusted odds ratio (AOR) 5.17 (95\% CI, 3.83-6.97), $P<0.001$ ]. Interestingly, previous diagnosis of polycystic ovary syndrome (PCOS) emerged as the major predictor of postpartum followup [AOR 5.27 (95\% CI, 3.51-8.70), $P<0.001$ ], even after stratification for the absence of counseling. Previous diagnosis of GDM, higher educational status, and insulin treatment were also relevant predictors. Overall, our data indicate that counseling intervention is effective, even if many women fail to return, whereas PCOS represents a new strong predictor of adherence to postpartum testing.
\end{abstract}

\section{Introduction}

Gestational diabetes mellitus (GDM) is historically defined as "any degree of glucose intolerance with onset or first recognition during pregnancy" [1]. Incidence of GDM is increasing worldwide for recent trends in obesity and advancing maternal age, significantly contributing to increased overall healthcare and economic costs $[2,3]$. Approximately $7 \%$ of all pregnancies are complicated by GDM, resulting in more than 200,000 cases annually [4-7]. Women with GDM are at high risk for short pregnancy complications, such as gestational hypertensive disorders, fetal macrosomia, shoulder dystocia, and cesarean delivery [8-10]. In addition, GDM constitutes a high risk for future type 2 diabetes mellitus (DM) and cardiovascular disease [11-13]. In particular, women with GDM, even with mild glucose intolerance, have up to seven times more risk of developing type $2 \mathrm{DM}$ compared to women with normoglycemic pregnancies [13-15], thus justifying recently recommended tighter diagnostic criteria for GDM [16].

Based on the compelling evidence that lifestyle intervention can effectively prevent or delay the development of type 2 DM [17-19], early identification of women at high risk of diabetes is very important. In this regard, postpartum is a critical period for early diagnosis and for planning prevention and intervention strategies [20-24]. Consistently, the Fifth International Workshop-Conference on Gestational Diabetes Mellitus Panel recommends that women with GDM have a 2-hour 75 gr oral glucose tolerance test (OGTT) at 6 weeks to 12 weeks postpartum [25]. Nevertheless, the majority of women fail to return for postpartum oral glucose testing (ppOGTT) [26-30]. Many reasons have been proposed for such lack of compliance, including poor communication between obstetrician and primary care provider, some confusion over the current guidelines, poor bridging from antepartum to postpartum care, lack of patient awareness, 
and a certain lack of interest in patient's personal health [30-32]. Therefore, in the last years, many tools have been tested to improve the coverage of screened women, including education intervention among women diagnosed with GDM, automated orders to primary care providers, and telephone and e-mail reminder messages to patients [33-37].

Based on this background, we designed a retrospective study in an Italian population in order to examine adherence rate to ppOGTT and evaluate the efficacy of educational intervention, identifying what are the predictor factors of compliance.

\section{Methods}

2.1. Study Population. 6770 Caucasian pregnant women attended the Hospital "Pugliese-Ciaccio" in Catanzaro (Calabria, Southern Italy), from January 2004 to December 2011, for GDM screening. Out of these, 1159 (17.1\%) were diagnosed with GDM, following the current criteria $[16,38]$. All consecutive pregnant women with GDM were included, except those with preexisting diabetes, as defined by ADA criteria [1]. Anamnestic information was obtained regarding age, instruction level, parity, previous GDM, family history of diabetes, self-reported prepregnancy weight, and previous polycystic ovary syndrome (PCOS), as diagnosed according to the Rotterdam criteria [39].

To promote adherence to ppOGTT, after January 2011, verbal and written counseling was given to 247 women at 35-40 weeks of pregnancy: they were informed about the increased risk for type $2 \mathrm{DM}$ and about the risks to start a new pregnancy in the presence of glucose intolerance. Then, pregnant ones were provided with a simple handout illustrating the risk of GDM, follow-up recommendations, and suggestions for a correct lifestyle, as type $2 \mathrm{DM}$ preventive strategy. The study was approved by the local ethics committee.

2.2. Statistical Analysis. The nonparametric Mann-Whitney $U$ test was used for comparisons of continuous variables and the 2-tailed Fisher exact test was used for comparisons of proportions. Generally, a significance level of 0.05 was set for a type I error in all analyses. Logistic regression analysis was used to evaluate individual effects of each patient's categorical characteristic, including counseling as possible predictor of ppOGTT postpartum testing. Odds Ratios (ORs) with 95\% confidence bounds were calculated. Linear regression analysis was employed to test the association of continue variables with adherence to followup. Each quantitative trait was tested for normality using the Shapiro-Wilk normality test and, when required, it was log-transformed. Data were analyzed with the SPSS 20.0 software. Post hoc statistical power calculations were performed using $\mathrm{G} *$ Power software 3.1.3 (Franz Faul, Kiel University, Kiel, Germany).

\section{Results}

1159 women were diagnosed as affected by GDM. Out of these, 374 (32.3\%) underwent postpartum diabetes screening

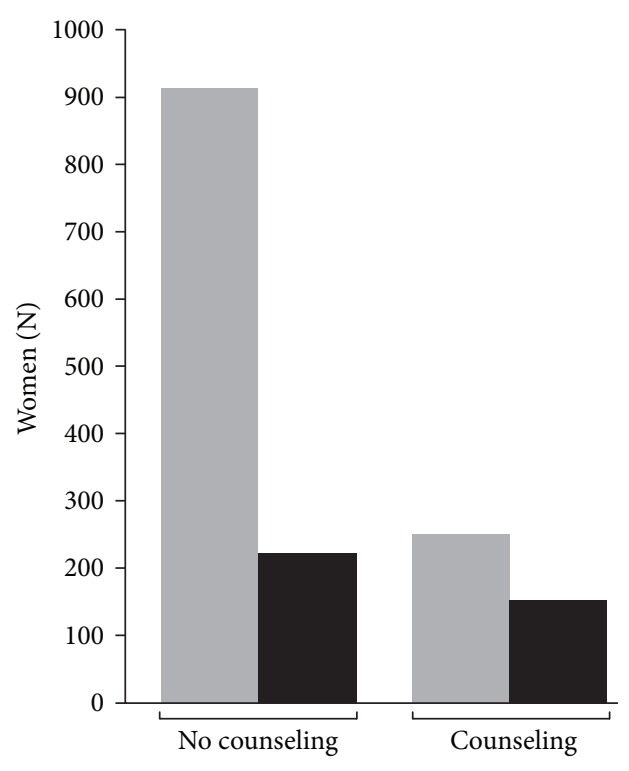

FIGURE 1: Adherence to ppOGTT in women with no counseling or after counseling. Gray bars, total women. Black bars, compliant women.

whereas the remaining 785 (67.7\%) did not. Table 1 summarizes demographic, anthropometric, clinical, and biochemical characteristics of both cohorts. Age at diagnosis, prevalence of previous GDM, instruction level, PCOS, fasting plasma glucose, and prevalence of insulin treatment were higher in the group adherent to followup compared with the group not adherent to followup. No difference was observed for prepregnancy BMI, familiarity for type $2 \mathrm{DM}$, and parity (Table 1).

3.1. Counseling Effectiveness. To test the effectiveness of verbal and written counseling, we compared the return rate of women receiving this intervention $(62.3 \%, 154 / 247)$ with that of women who did not receive this intervention $(24.1 \%, 220 / 912)$ (Figure 1). After adjustment for possible confounders, logistic regression analysis showed a strong association between counseling intervention and adherence to ppOGTT [adjusted OR (AOR) 5.17 (95\% CI, 3.83-6.97), $P<$ 0.001] (Table 2). After suitable stratifications, adherence to followup appeared higher among women with middle/high educational status [AOR 5.25 (95\% CI, 3.60-7.65), $P<$ 0.001 ] with respect to women with lower educational status [AOR 4.08 (95\% CI, 2.26-7.38), $P<0.001$ ]; higher among women $\geq 30$ years old [AOR 5.64 (95\% CI, 3.90-8.14), $P<$ 0.001 ], compared with younger women [AOR 4.66 (95\% CI, 2.71-8.01), $P<0.001$; higher among multigravid women [AOR 5.91 (95\% CI, 3.93-8.89), $P<0.001$ ] with respect to primigravidas [AOR 4.46 (95\% CI, 2.86-6.94), $P<0.001$ ] (Table 2). In all cases statistical power exceeded $95 \%$.

3.2. Other Predictors of $p p O G T T$. To identify other predictors of ppOGTT, clinical and biochemical parameters that may influence screening rates were employed into a logistic regression analysis (Table 3(a)). As expected, a previous diagnosis 
TABLE 1: General characteristics of the GDM population.

\begin{tabular}{|c|c|c|c|}
\hline & Followup $(n=374)$ & No followup $(n=785)$ & $P$ value \\
\hline Race & Caucasian & Caucasian & - \\
\hline Age (yr), median & 36 & 33 & $<0.001$ \\
\hline Range & $18-48$ & $18-46$ & - \\
\hline BMI $\left(\mathrm{kg} / \mathrm{m}^{2}\right)$, median & 25.3 & 24.5 & 0.175 \\
\hline Range & $19-44.8$ & $17.6-45$ & - \\
\hline Familiarity for type $2 \mathrm{DM}(n)$ & 270 & 535 & 0.150 \\
\hline Previous GDM & 72 & 45 & $<0.001$ \\
\hline Parity $(n)$, median & 2 & 2 & 0.177 \\
\hline Range & $1-5$ & $1-6$ & - \\
\hline$>1$ & 207 & 438 & 0.900 \\
\hline \multicolumn{4}{|l|}{ Educational status } \\
\hline Low & 71 & 384 & $<0.001$ \\
\hline Middle & 256 & 356 & $<0.001$ \\
\hline High & 47 & 45 & $<0.001$ \\
\hline FPG (mg/dL), median & 94 & 92 & 0.020 \\
\hline Range & $70-121$ & $72-126$ & - \\
\hline Insulin treatment & 147 & 253 & 0.021 \\
\hline PCOS & 72 & 37 & $<0.001$ \\
\hline
\end{tabular}

Mann-Whitney $U$ test was used for comparison of continuous traits. 2-tailed Fisher exact test was used for comparison of proportions. SD: standard deviation; BMI: body mass index; low educational status: primary school; middle educational status: secondary school; high educational status: university degree; FPG: fasting plasma glucose; PCOS: polycystic ovary syndrome.

TABLE 2: Effect of counseling on follow-up adherence.

\begin{tabular}{|c|c|c|c|c|c|c|}
\hline & Stratification & Followup $(n=374)$ & No followup $(n=785)$ & OR $(95 \% \mathrm{CI})$ & $P$ value & Statistical power \\
\hline Counseling $(n)$ & \multirow{2}{*}{ None } & 154 & 93 & \multirow{2}{*}{$5.17(3.83-6.97)$} & \multirow{2}{*}{$<0.001$} & \multirow{2}{*}{$>95.0 \%$} \\
\hline No counseling $(n)$ & & 220 & 692 & & & \\
\hline Counseling $(n)$ & \multirow{2}{*}{ Low educational status } & 24 & 47 & \multirow{2}{*}{$4.08(2.26-7.38)$} & \multirow{2}{*}{$<0.001$} & \multirow{2}{*}{$>95.0 \%$} \\
\hline No counseling $(n)$ & & 43 & 341 & & & \\
\hline Counseling $(n)$ & \multirow{2}{*}{ Middle/high educational status } & 130 & 173 & \multirow{2}{*}{$5.25(3.60-7.65)$} & \multirow{2}{*}{$<0.001$} & \multirow{2}{*}{$>95.0 \%$} \\
\hline No counseling $(n)$ & & 50 & 351 & & & \\
\hline Counseling $(n)$ & \multirow{2}{*}{ Age $\leq 30 \mathrm{yr}$} & 40 & 58 & \multirow{2}{*}{$4.66(2.71-8.01)$} & \multirow{2}{*}{$<0.001$} & \multirow{2}{*}{$>95.0 \%$} \\
\hline No counseling $(n)$ & & 30 & 190 & & & \\
\hline Counseling $(n)$ & \multirow{2}{*}{ Age $\geq 31 \mathrm{yr}$} & 108 & 168 & \multirow{2}{*}{$5.64(3.90-8.14)$} & \multirow{2}{*}{$<0.001$} & \multirow{2}{*}{$>95.0 \%$} \\
\hline No counseling $(n)$ & & 56 & 509 & & & \\
\hline Counseling $(n)$ & \multirow{2}{*}{ Parity $=1$} & 67 & 100 & \multirow{2}{*}{$4.46(2.86-6.94)$} & \multirow{2}{*}{$<0.001$} & \multirow{2}{*}{$>95.0 \%$} \\
\hline No counseling $(n)$ & & 45 & 301 & & & \\
\hline Counseling $(n)$ & \multirow{2}{*}{ Parity $\geq 2$} & 87 & 120 & \multirow{2}{*}{$5.91(3.93-8.89)$} & \multirow{2}{*}{$<0.001$} & \multirow{2}{*}{$>95.0 \%$} \\
\hline No counseling $(n)$ & & 48 & 391 & & & \\
\hline
\end{tabular}

ORs (95\% CI) were estimated using logistic regression models adjusted for prepregnancy BMI, familial history of type 2 DM, previous GDM, parity. Post-hoc statistical power calculations were performed using $\mathrm{G} *$ Power software 3.1, entering $R$-squared multiple correlation coefficient obtained with regression for each trait.

of GDM, as well as a higher educational status, strongly correlated with a better adherence to ppOGTT [AOR 4.82 (95\% CI, 3.17-7.33), $P<0.001$, and AOR 4.06 (95\% CI, 3.025.45) $P<0.001$, resp.] (Table 3(a)). Also, insulin treatment during pregnancy was a predictor of follow-up adherence [AOR 2.32 (95\% CI, 1.76-3.05), $P<0.001$ ]. A mild association between prepregnancy BMI and ppOGTT was observed among overweight/obese women when compared with lean women [AOR 1.41 (95\% CI, 1.09-1.81), $P=0.008$ ] (Table 3(a)). Interestingly, a previous diagnosis of PCOS emerged as the major predictor of postpartum evaluation of glucose tolerance in women with GDM [AOR 5.27 (95\% CI, 3.368.27), $P<0.001$ ] (Table 3(a)). No association was observed with other factors, such as family history of type $2 \mathrm{DM}$ and parity (Table 3(a)). To exclude influence of counseling intervention on detected predictors, a multiple regression analysis, after stratification for the absence of counseling, has been performed. As shown in Table 3(a), no substantial change emerged for any factor, indicating that their predicting effect was independent of counseling. 
TABLE 3: (a) Multiple logistic regression analysis for predicting follow-up adherence among Italian women with GDM. (b) Effects of continuous clinical and biochemical traits on follow-up adherence.

(a)

\begin{tabular}{|c|c|c|c|c|c|c|c|}
\hline & $\begin{array}{l}\text { Followup } \\
(n=374)\end{array}$ & $\begin{array}{l}\text { No followup } \\
\quad(n=785)\end{array}$ & OR $1(95 \% \mathrm{CI})$ & $P$ value 1 & $\begin{array}{c}\text { Statistical } \\
\text { power }\end{array}$ & OR $2(95 \% \mathrm{CI})$ & $P$ value 2 \\
\hline Age $(\geq 31$ yr versus $\leq 30 \mathrm{yr})$ & $\begin{array}{l}69 \text { versus } \\
305\end{array}$ & 174 versus 611 & $1.18(0.89-1.58)$ & 0.242 & $22.1 \%$ & $1.27(0.88-1.82)$ & 0.198 \\
\hline Familiarity for type $2 \mathrm{DM}(\%)$ & $270(72.2)$ & $535(68.2)$ & $1.21(0.92-1.58)$ & 0.178 & $31.6 \%$ & $0.94(0.68-1.31)$ & 0.097 \\
\hline \multicolumn{8}{|l|}{ Prepregnancy BMI $\left(\mathrm{kg} / \mathrm{m}^{2}\right)$} \\
\hline$<25$ versus $\geq 25$ & $\begin{array}{l}174 \text { versus } \\
200\end{array}$ & $\begin{array}{c}426 \text { versus } \\
359\end{array}$ & $1.41(1.09-1.81)$ & 0.008 & $81.5 \%$ & $1.74(1.27-2.37)$ & 0.001 \\
\hline Previous GDM (\%) & $72(19.3)$ & $45(5.7)$ & $4.82(3.17-7.33)$ & $<0.001$ & $>95.0 \%$ & $5.30(3.26-8.61)$ & $<0.001$ \\
\hline Parity (1 versus $\geq 2$ ) & $\begin{array}{l}167 \text { versus } \\
207\end{array}$ & $\begin{array}{l}346 \text { versus } \\
439\end{array}$ & $1.03(0.80-1.32)$ & 0.800 & $5.7 \%$ & $1.11(0.82-1.51)$ & 0.500 \\
\hline \multicolumn{8}{|l|}{ Educational status } \\
\hline Middle/high versus low & $\begin{array}{c}303 \text { versus } \\
71\end{array}$ & $\begin{array}{l}401 \text { versus } \\
384\end{array}$ & $4.06(3.02-5.45)$ & $<0.001$ & $>95.0 \%$ & $3.54(2.48-5.06)$ & $<0.001$ \\
\hline Insulin treatment $(\%)$ & $147(39.3)$ & $253(32.2)$ & $2.32(1.76-3.05)$ & $<0.001$ & $>95.0 \%$ & $2.63(1.90-3.66)$ & $<0.001$ \\
\hline $\operatorname{PCOS}(\%)$ & $72(19.3)$ & $37(4.7)$ & $5.27(3.36-8.27)$ & $<0.001$ & $>95.0 \%$ & $5.36(3.24-8.85)$ & $<0.001$ \\
\hline
\end{tabular}

OR 1: odd ratio after adjustment for any possible confounder; OR 2: As OR 1, but after stratification for absence of counseling; CI: confidence interval; Post-hoc statistical power calculations were performed using $\mathrm{G} *$ Power software 3.1, entering $R$-squared multiple correlation coefficient obtained with regression for each trait. Low educational status: primary school; middle educational status: secondary school; high educational status: university degree; PCOS: polycystic ovary syndrome.

(b)

\begin{tabular}{|c|c|c|c|c|}
\hline & Followup $(n=374)$ & No followup $(n=785)$ & $P$ value & Statistical power \\
\hline Age $(y r)$, mean \pm SD & $34.5 \pm 5.2$ & $33.1 \pm 4.8$ & $<0.001$ & $>95.0 \%$ \\
\hline Prepregnancy BMI $\left(\mathrm{kg} / \mathrm{m}^{2}\right)$, mean $\pm \mathrm{SD}$ & $25.9 \pm 4.5$ & $25.7 \pm 4.7$ & 0.265 & $67.4 \%$ \\
\hline $\mathrm{FPG}(\mathrm{mg} / \mathrm{dL})$, mean $\pm \mathrm{SD}$ & $92.8 \pm 9.0$ & $91.2 \pm 10.7$ & 0.027 & $>95.0 \%$ \\
\hline Week at diagnosis $(n)$, mean \pm SD & $25.3 \pm 4.9$ & $27.2 \pm 3.4$ & $<0.001$ & $>95.0 \%$ \\
\hline
\end{tabular}

Continuous variables were compared using linear regression models adjusted for familial history of type 2 DM, parity, and prepregnancy BMI (when appropriate). Post-hoc statistical power calculations were performed using $\mathrm{G} *$ Power software 3.1, entering partial $R$-squared obtained with regression for each trait. FPG: fasting plasma glucose; PCOS: polycystic ovary syndrome. All variables have been log-transformed to better approximate a normal distribution.

When continuous variables were tested, significant association of ppOGTT was observed with earlier diagnosis of GDM $(P<0.001)$ and age $(P<0.001)$ and fasting plasma glucose $(P=0.027)$ at diagnosis of GDM (Table $3(b))$. For all these traits statistical power exceeded $95 \%$.

\section{Discussion}

Herein, we investigated the rate of ppOGTT in Calabrian women, a Southern Italian population characterized by higher prevalence of GDM, type 2 DM, and obesity, as compared to the entire Italian population (http://www.istat.it). As reported in this study, pregnant women who underwent prepartum counseling had a significantly better follow-up adherence rate than those who had no counseling. Counseling was more effectiveness in older women and in women with higher educational level and with previous pregnancies. This is consistent with a major degree of awareness of health risks in these women with respect to younger women, women with low educational status, or primigravidas. For the first time, previous diagnosis of PCOS emerged as the stronger predictor of ppOGTT, with a similar and independent strength with respect to counseling. As an explanation for this, women with PCOS might be more willing to accept medical recommendations, since they often experience unpleasant clinical manifestations such as menstrual irregularity, infertility, and hirsutism. Moreover, because patients with PCOS are often treated with metformin, a widely used antidiabetic drug, these women might be more aware of the risk of type $2 \mathrm{DM}$ and might have more contacts within the health-care system.

In a similar way to other reports $[26,27,40]$, our results indicate that the most compliant ones were older women, with a previous diagnosis of GDM, higher educational levels, overweight, or obese and those with insulin treatment, higher FPG, and an early diagnosis of GDM. It is plausible that these women may have had greater awareness of their risk for becoming diabetics.

\section{Conclusions}

In summary, we show that counseling is an effective, inexpensive, and simple tool in increasing ppOGTT rates for women with GDM. Moreover, patients with a previous diagnosis 
of PCOS were found to be significantly associated with a higher compliance rate for this test. Therefore, counseling can be more effectively targeted based on these observations. Further studies are needed to see whether our findings can be generalized to other populations.

\section{Conflict of Interests}

The authors declare no potential conflict of interests with respect to the authorship and/or publication of this paper.

\section{Authors' Contribution}

C. Capula designed the study and recruited patients; E. Chiefari contributed to the study design and wrote the first draft of the paper; E. Chiefari, S. Iiritano, and B. Arcidiacono analyzed data; C. Capula, A. Vero, L. Puccio, and V. Pullano recruited patients; D. Foti and A. Brunetti contributed to critical revision and writing of the paper; R. Vero coordinated and supervised the study. All authors discussed the results and commented on the paper. C. Capula and E. Chiefari contributed equally to this work.

\section{Acknowledgments}

The authors thank the staff of the Diabetes Unit of the Azienda Ospedaliera Pugliese-Ciaccio of Catanzaro, Italy, particularly Mrs. M. Zangari, Mrs. C. Lombardo, Mrs. T. Marghella, Mr. V. Cristofaro, and Mrs. G. Procopio, for their precious help in the recruitment and examination of patients. Dr. C. Capula acknowledges a scholarship from Eli Lilly S.p.A.

\section{References}

[1] American Diabetes Association, "Diagnosis and classification of diabetes mellitus," Diabetes Care, vol. 32, supplement 1, pp. S62-S67, 2009.

[2] K. J. Hunt and K. L. Schuller, "The increasing prevalence of diabetes in pregnancy," Obstetrics and Gynecology Clinics of North America, vol. 34, no. 2, pp. 173-199, 2007.

[3] L. L. Lipscombe and J. E. Hux, "Trends in diabetes prevalence, incidence, and mortality in Ontario, Canada 1995-2005: a population-based study," The Lancet, vol. 369, no. 9563, pp. 750756, 2007.

[4] J. M. Lawrence, R. Contreras, W. Chen, and D. A. Sacks, “Trends in the prevalence of preexisting diabetes and gestational diabetes mellitus among a racially/ethnically diverse population of pregnant women, 1999-2005," Diabetes Care, vol. 31, no. 5, pp. 899-904, 2008.

[5] A. Ferrara, H. S. Kahn, C. P. Quesenberry, C. Riley, and M. M. Hedderson, "An increase in the incidence of gestational diabetes mellitus: Northern California, 1991-2000," Obstetrics \& Gynecology, vol. 103, no. 4, pp. 526-533, 2004.

[6] D. Getahun, C. Nath, C. V. Ananth, M. R. Chavez, and J. C. Smulian, "Gestational diabetes in the United States: temporal trends 1989 through 2004," The American Journal of Obstetrics and Gynecology, vol. 198, no. 5, pp. 525.el-525.e5, 2008.
[7] L. Jovanovic and D. J. Pettitt, "Gestational diabetes mellitus," Journal of the American Medical Association, vol. 286, no. 20, pp. 2516-2518, 2001.

[8] B. E. Metzger, L. P. Lowe, R. A. Dyer et al., "Hyperglycemia and adverse pregnancy outcomes," The New England Journal of Medicine, vol. 358, no. 19, pp. 1991-2002, 2008.

[9] O. Verier-Mine, "Outcomes in women with a history of gestational diabetes. Screening and prevention of type 2 diabetes. Literature review," Diabetes \& metabolism, vol. 36, no. 6, pp. 595-616, 2010

[10] E. P. O'Sullivan, G. Avalos, M. O’Reilly, M. C. Dennedy, G. Gaffney, and F. Dunne, "Atlantic Diabetes in Pregnancy (DIP): the prevalence and outcomes of gestational diabetes mellitus using new diagnostic criteria," Diabetologia, vol. 54, no. 7, pp. 1670-1675, 2011.

[11] L. Bellamy, J.-P. Casas, A. D. Hingorani, and D. Williams, "Type 2 diabetes mellitus after gestational diabetes: a systematic review and meta-analysis," The Lancet, vol. 373, no. 9677, pp. 1773-1779, 2009.

[12] S. I. Dawson, "Glucose tolerance in pregnancy and the longterm risk of cardiovascular disease," Diabetes Research and Clinical Practice, vol. 85, no. 1, pp. 14-19, 2009.

[13] S. D. Sullivan, J. G. Umans, and R. Ratner, "Gestational diabetes: implications for cardiovascular health," Current Diabetes Reports, vol. 12, no. 1, pp. 43-52, 2012.

[14] D. B. Carr, K. M. Newton, K. M. Utzschneider et al., "Modestly elevated glucose levels during pregnancy are associated with a higher risk of future diabetes among women without gestational diabetes mellitus," Diabetes Care, vol. 31, no. 5, pp. 1037-1039, 2008.

[15] R. Retnakaran and B. R. Shah, "Mild glucose intolerance in pregnancy and risk of cardiovascular disease: a populationbased cohort study," CMAJ, vol. 181, no. 6-7, pp. 371-376, 2009.

[16] International Association Of Diabetes And Pregnancy Study Groups Consensus Panel, "International Association of Diabetes and Pregnancy Study Groups recommendations on the diagnosis and classification of hyperglycemia in pregnancy," Diabetes Care, vol. 33, no. 3, pp. 676-682, 2010.

[17] J. Tuomilehto, J. Lindström, J. G. Eriksson et al., "Prevention of type 2 diabetes mellitus by changes in lifestyle among subjects with impaired glucose tolerance," The New England Journal of Medicine, vol. 344, no. 18, pp. 1343-1350, 2001.

[18] L. J. England, P. M. Dietz, T. Njoroge et al., "Preventing type 2 diabetes: public health implications for women with a history of gestational diabetes mellitus," The American Journal of Obstetrics and Gynecology, vol. 200, no. 4, pp. 365.e1-365.e8, 2009.

[19] T. Saaristo, L. Moilanen, E. Korpi-Hyövälti et al., "Lifestyle intervention for prevention of type 2 diabetes in primary health care: one-year follow-up of the finnish national diabetes prevention program (FIN-D2D)," Diabetes Care, vol. 33, no. 10, pp. 2146-2151, 2010.

[20] J. Ogonowski and T. Miazgowski, "The prevalence of 6 weeks postpartum abnormal glucose tolerance in Caucasian women with gestational diabetes," Diabetes Research and Clinical Practice, vol. 84, no. 3, pp. 239-244, 2009.

[21] R. Retnakaran, Y. Qi, M. Sermer, P. W. Connelly, B. Zinman, and A. J. G. Hanley, "Comparison of National Diabetes Data Group and American Diabetes Association diagnostic criteria for gestational diabetes in their identification of postpartum risk of glucose intolerance," Diabetes Research and Clinical Practice, vol. 85, no. 1, pp. 40-46, 2009. 
[22] Committee on Obstetric Practice, "ACOG Committee Opinion no. 435: postpartum screening for abnormal glucose tolerance in women who had gestational diabetes mellitus," Obstetrics \& Gynecology, vol. 113, no. 6, pp. 1419-1421, 2009.

[23] C. Kim, "Managing women with gestational diabetes mellitus in the postnatal period," Diabetes, Obesity and Metabolism, vol. 12, no. 1, pp. 20-25, 2010.

[24] S. McClean, D. Farrar, C. A. Kelly, D. J. Tuffnell, and D. C. Whitelaw, "The importance of postpartum glucose tolerance testing after pregnancies complicated by gestational diabetes," Diabetic Medicine, vol. 27, no. 6, pp. 650-654, 2010.

[25] B. E. Metzger, T. A. Buchanan, D. R. Coustan et al., "Summary and recommendations of the Fifth International WorkshopConference on Gestational Diabetes Mellitus," Diabetes Care, vol. 30, supplement 2, pp. S251-S260, 2007.

[26] A. Tovar, L. Chasan-Taber, E. Eggleston, and E. Oken, "Postpartum screening for diabetes among women with a history of gestational diabetes mellitus," Preventing Chronic Disease, vol. 8, no. 6, article A124, 2011.

[27] A. Ferrara, T. Peng, and C. Kim, "Trends in postpartum diabetes screening and subsequent diabetes and impaired fasting glucose among women with histories of gestational diabetes mellitus: a report from the translating research into action for diabetes (TRIAD) study," Diabetes Care, vol. 32, no. 2, pp. 269-274, 2009.

[28] C. Kim, B. P. Tabaei, R. Burke et al., "Missed opportunities for type 2 diabetes mellitus screening among women with a history of gestational diabetes mellitus," The American Journal of Public Health, vol. 96, no. 9, pp. 1643-1648, 2006.

[29] M. A. Russell, M. G. Phipps, C. L. Olson, H. G. Welch, and M. W. Carpenter, "Rates of postpartum glucose testing after gestational diabetes mellitus," Obstetrics and Gynecology, vol. 108, no. 6, pp. 1456-1462, 2006.

[30] K. V. Smirnakis, L. Chasan-Taber, M. Wolf, G. Markenson, J. L. Ecker, and R. Thadhani, "Postpartum diabetes screening in women with a history of gestational diabetes," Obstetrics and Gynecology, vol. 106, no. 6, pp. 1297-1303, 2005.

[31] M. Stasenko, Y. W. Cheng, T. McLean, A. C. Jelin, L. Rand, and A. B. Caughey, "Postpartum follow-up for women with gestational diabetes mellitus," The American Journal of Perinatology, vol. 27, no. 9, pp. 737-742, 2010.

[32] E. Korpi-Hyövälti, S. Heinonen, U. Schwab, D. E. Laaksonen, and L. Niskanen, "How can we increase postpartum glucose screening in women at high risk for gestational diabetes mellitus?" Primary Care Diabetes, vol. 2012, Article ID 519267, 6 pages, 2012.

[33] K. J. Hunt, S. L. Logan, D. L. Conway, and J. E. Korte, "Postpartum screening following gdm: how well are we doing?" Current Diabetes Reports, vol. 10, no. 3, pp. 235-241, 2010.

[34] M. L. Hunsberger, R. J. Donatelle, K. Lindsay, and K. D. Rosenberg, "Physician care patterns and adherence to postpartum glucose testing after gestational diabetes mellitus in Oregon," PLoS One, vol. 7, no. 10, Article ID e47052, 2012.

[35] A. K. Shea, B. R. Shah, H. D. Clark et al., "The effectiveness of implementing a reminder system into routine clinical practice: does it increase postpartum screening in women with gestational diabetes?" Chronic Diseases in Canada, vol. 31, no. 2, pp. 58-64, 2011.

[36] M. Stasenko, J. Liddell, Y. W. Cheng, T. N. Sparks, M. Killion, and A. B. Caughey, "Patient counseling increases postpartum follow-up in women with gestational diabetes mellitus," The American Journal of Obstetrics and Gynecology, vol. 204, no. 6, pp. 522.el-522.e6, 2011.
[37] K. K. Vesco, P. M. Dietz, J. Bulkley et al., "A system-based intervention to improve postpartum diabetes screening among women with gestational diabetes," The American Journal of Obstetrics \& Gynecology, vol. 207, no. 4, Article ID 283.e1-6, 2012.

[38] B. E. Metzger and D. R. Coustan, "Summary and recommendations of the fourth international workshop- conference on gestational diabetes mellitus," Diabetes Care, vol. 21, supplement 2, pp. B161-B167, 1998.

[39] Rotterdam ESHRE/ASRM-Sponsored PCOS Consensus Workshop Group, "Revised 2003 consensus on diagnostic criteria and long-term health risks related to polycystic ovary syndrome," Fertility and Sterility, vol. 81, no. 1, pp. 19-25, 2004.

[40] S. Kwong, R. S. Mitchell, P. A. Senior, and C. L. Chik, "Postpartum diabetes screening: adherence rate and the performance of fasting plasma glucose versus oral glucose tolerance test," Diabetes Care, vol. 32, no. 12, pp. 2242-2244, 2009. 


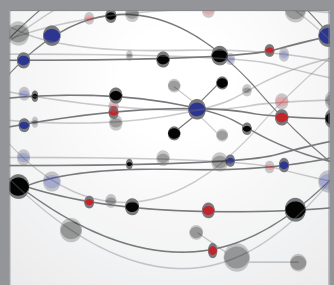

The Scientific World Journal
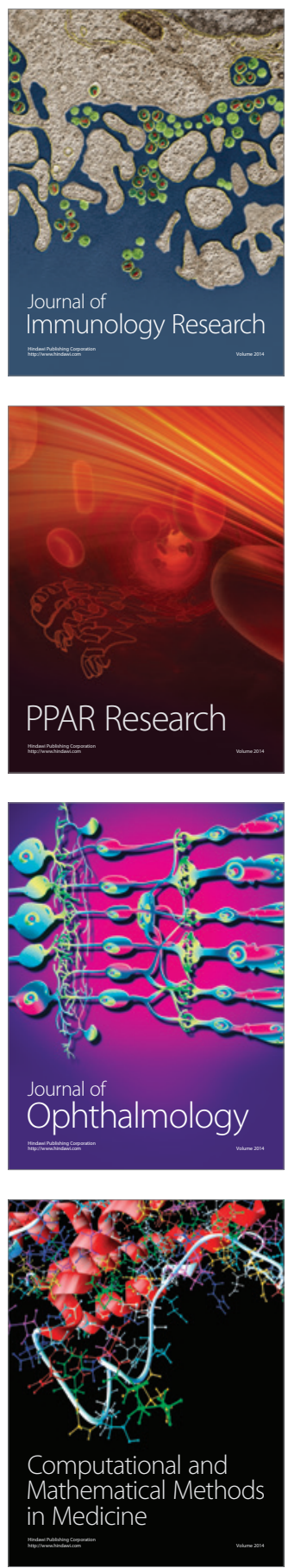

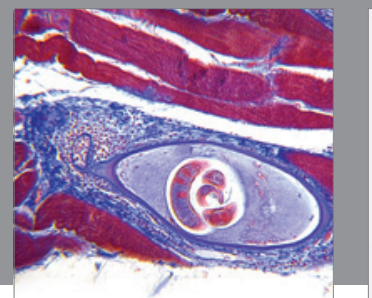

Gastroenterology

Research and Practice
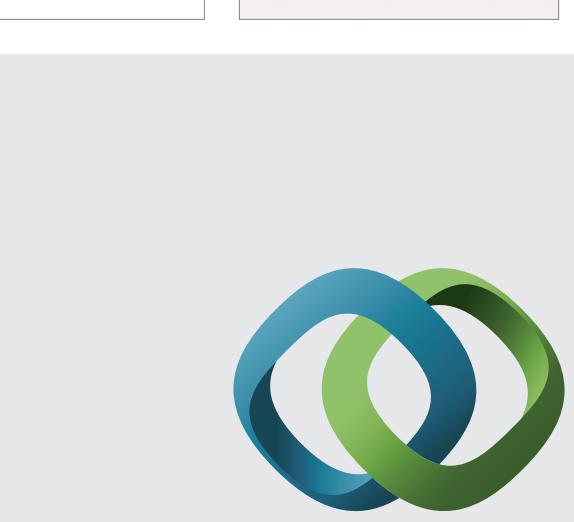

\section{Hindawi}

Submit your manuscripts at

http://www.hindawi.com
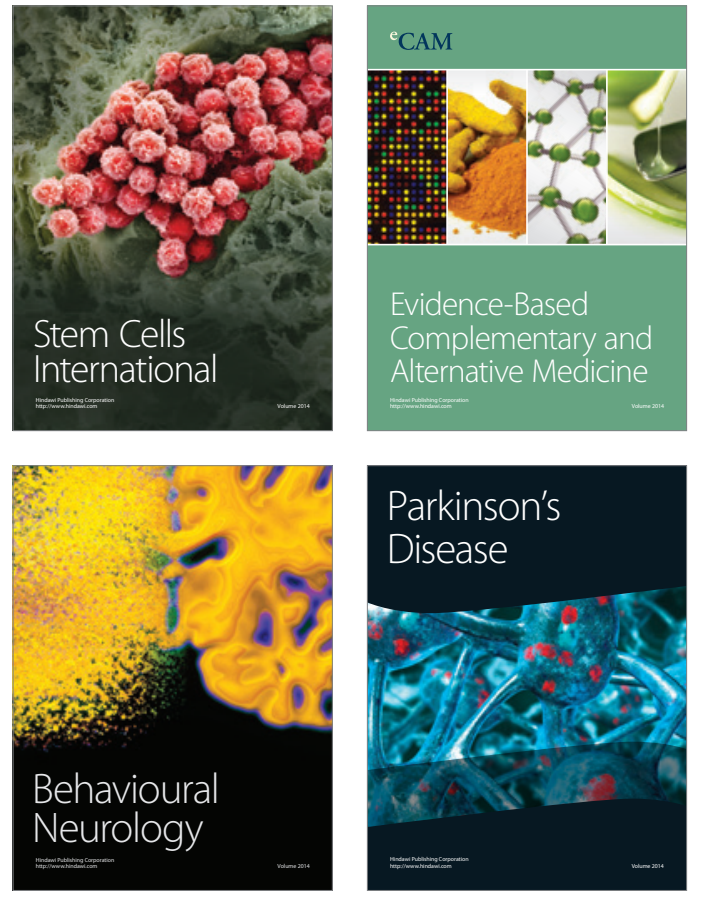
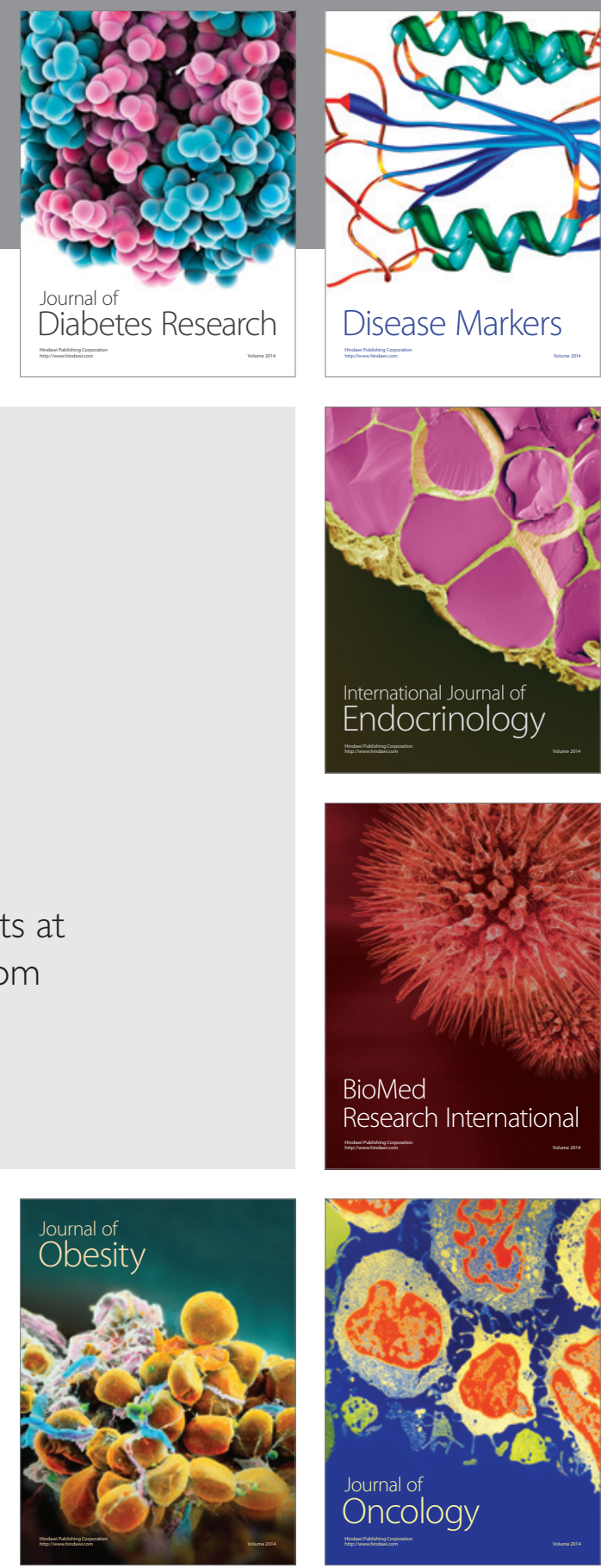

Disease Markers
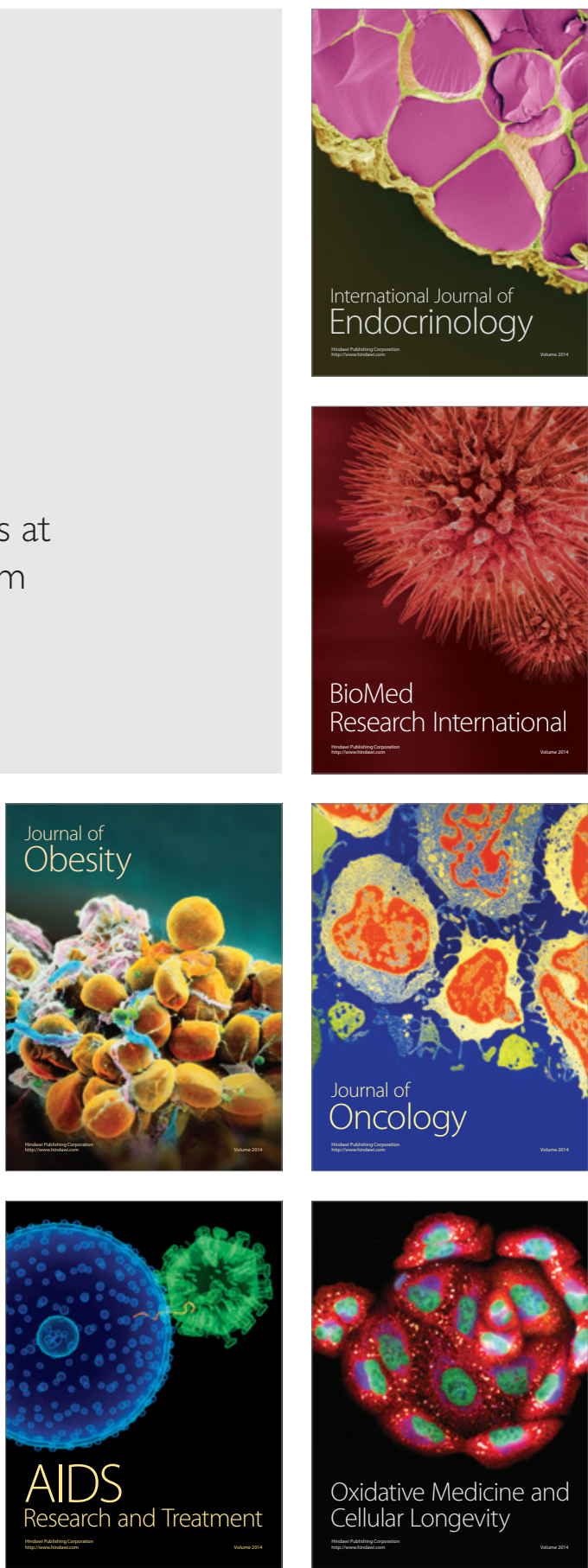